\title{
Quality of life and glycemic control in adolescents with type I diabetes and the impact of an education intervention
}

This article was published in the following Dove Press journal:

International Journal of General Medicine

I8 February 201 I

Number of times this article has been viewed

\author{
Mostafa A Abolfotouh",* \\ Mofida M Kamal',* \\ Mohamed D El-Bourgy,** \\ Sherine G Mohamed ${ }^{2, *}$ \\ 'King Abdullah International Medical \\ Research Center (KAIMRC), King \\ Saud bin Abdulaziz University \\ for Health Sciences (KSAU-HS), \\ Riyadh, Kingdom of Saudi Arabia; \\ ${ }^{2}$ Department of Health Administration \\ and Behavioral Sciences, High \\ Institute of Public Health, Alexandria \\ University, Alexandria, Egypt; *All \\ authors contributed equally \\ to this work
}

Objective: To assess quality of life (QoL) and glycemic control in adolescents with type 1 diabetes and to investigate the impact of an educational program.

Methods: A quasiexperimental study with nonrandomized experimental and control groups was conducted in which a total of 503 adolescents with type 1 diabetes completed a questionnaire using the Diabetes Quality of Life Instrument for Youth. Adolescents were then assigned to experimental and control groups. The experimental group was subjected to four 120-minute sessions of an educational program over a period of 4 months. Extracted medical chart data included the duration of diabetes, insulin dosage, and most recent hemoglobin A1c levels. Analysis of covariance was used to detect the impact of intervention.

Results: The overall mean QoL score (\%) was $76.51 \pm 9.79$, with good QoL in $38 \%$ of all adolescents. Poorer QoL was significantly associated with older age $(P<0.001)$, more hospital admissions in the last 6 months $(P=0.006)$, higher levels of depression $(P<0.001)$, poor self-esteem $(P<0.001)$, and poor self-efficacy $(P<0.001)$. There was significant deterioration in all domains of $\mathrm{QoL}$ in the experimental group after intervention. However, this deterioration was significantly less severe than in the control group. Between-group effects on total knowledge, adherence to exercise, glucose monitoring, treatment, self-efficacy, family contribution to management, glycemic control, and satisfaction with life were significantly in favor of the experimental group.

Conclusion: Education intervention for adolescents with type 1 diabetes could be a safeguard against possible deterioration in QoL and glycemic control over time.

Keywords: adolescents, diabetes, QoL, glycemic, intervention

\section{Introduction}

Adolescents with type 1 diabetes are challenged to adapt to a lifestyle that requires the self-management of dietary practices, exercise behaviors, and insulin adjustment in addition to developing autonomy and self-identity. The rapid biological changes that occur during adolescence and the need to learn to manage a chronic illness can place adolescents at risk for poor metabolic control and life adjustment difficulties., ${ }^{1,2}$ These considerable demands may interfere with adolescents' ability to negotiate important developmental tasks, including the ability to achieve good psychological adjustment $^{2}$ and improve overall quality of life (QoL). ${ }^{3,4}$ Lower QoL scores were associated with older age, poor glycemic control, increasing hypoglycemic episodes, complications, lower levels of education and outcome, self-reported depression, and female gender. ${ }^{5}$
Correspondence: Mostafa A Abolfotouh King Abdullah International Medical Research Center (KAIMRC), King Saud bin Abdulaziz University for Health Sciences (KSAU-HS), Riyadh II 426, POB 22490, Kingdom of Saudi Arabia Tel +966503659204

Fax +966 I 2520772

Email mabolfotouh@gmail.com 
The goal of diabetes education is to help patients acquire the knowledge, information, self-care practices, coping skills, and attitudes required for the effective self-management of their diabetes. ${ }^{6}$ The literature shows that educational and counseling interventions designed to facilitate the development of diabetes self-management skills can improve QoL in people with diabetes. ${ }^{\text {? }}$

The effect of educational programs on glycemic control differs among studies. Some studies have reported improvement in glycemic control. ${ }^{8-10}$ Matam et al ${ }^{9}$ stated that their behavioral intervention led to an improvement in glycemic control, which was maintained at a 3-month follow-up period. Tang et $\mathrm{al}^{10}$ reported that glycosylated hemoglobin (HbAlc) decreased from a baseline level of $9.2 \%$ to $8.6 \%$ after implementing their self-management intervention. Ellis et $\mathrm{al}^{8}$ found that in adolescents who underwent an intervention program, $\mathrm{HbAlc}$ was found to have declined by an average of $0.8 \%$.

The purpose of this study was to assess QoL and glycemic control and the impact of an educational program on adolescents with type 1 diabetes in Alexandria City, Egypt. This knowledge can provide direction for the establishment of individualized interventions to assist in lifelong adaptation to a chronic illness.

\section{Patients and methods Study setting}

In this study, we included diabetic students in the city of Alexandria who had received follow-up care in one of two main diabetes outpatient clinics: the El-Shatby Pediatric Hospital and the Sporting Student's Insurance Hospital. The Sporting Student's Hospital is affiliated with Egypt's health insurance organization, and the El-Shatby Pediatric Hospital is affiliated with the Egyptian Ministry of Health. In both hospitals, children or students can be hospitalized and treated with outpatient care in the specialized clinics. Diabetes clinics in these two hospitals are responsible for managing all diabetic children and adolescents in Alexandria and the West Delta in terms of diagnosis, treatment, hospitalization, the provision of drugs, and health education. The type of care provided in the two facilities was similar, with no special formal educational training being given to the diabetic students.

\section{Study design}

A cross-sectional, interview-based study design was used to study the QoL and its determinants in diabetic adolescents. A quasiexperimental study using a longitudinal approach to compare two nonrandomized groups (experimental and control groups) with pre- and post-tests was conducted to evaluate the impact of an intervention program on QoL and glycemic control in a subset of adolescents who completed the preliminary interview. The experimental group received the group intervention monthly for 4 consecutive months, whereas the control group did not receive any intervention. Both groups were post-tested 6 months after completion of the intervention.

\section{Target population and sampling technique}

The target population was diabetic adolescents of both sexes (between the ages of 12 and 20 years) who were attending the diabetes outpatient clinics in the El-Shatby Pediatric Hospital and the Sporting Student's Insurance Hospital. Using EPI Info ${ }^{\mathrm{TM}}$ Version 6.4 (Centers for Disease Control and Prevention, Atlanta, GA, USA), we determined the sample size needed to assess the QoL of adolescents based on the prevalence of poor QoL of 5\% of adolescents with type 1 diabetes ${ }^{11}$ with $1.8 \%$ precision and a $95 \%$ confidence limit. The sample size required was 563 adolescents. A total of 503 diabetic adolescents who attended the previously mentioned two outpatient clinics during the period of the cross-sectional study (4 months) and agreed to participate were allocated (89.3\% response rate).

For the intervention program, to calculate the sample size, we used published recommendations to detect differences in psychosocial measures. ${ }^{12}$ A sample size of 286 adolescents (143 in each group) was required to detect an increase of $10 \%$ in the percentage mean score of total QoL after intervention more than the control group, ${ }^{12}$ considering a $\beta$ error of $20 \%$ and an $\alpha$ error of 5\% using a two-sided analysis with a Chi-squared $\left(\chi^{2}\right)$ test. The number of patients who attended the previously mentioned two hospitals during the period of intervention (4 months) and agreed to participate in the program was 243 ( $85 \%$ response rate). The experimental group comprised 121 adolescents who were the first to come to the clinics for follow-up. All of the remaining adolescents $(n=122)$ comprised the control group. Both groups were subjected to the pre- and post-tests. No statistical differences were detected between the intervention and nonintervention groups based on age $\left(\chi^{2}=2.311, P=0.43\right)$, gender $\left(\chi^{2}=0.47\right.$, $P=0.85)$, or socioeconomic status $\left(\chi^{2}=1.11, P=0.76\right)$.

\section{Measures}

\section{An interview questionnaire}

A predesigned structured interview questionnaire was used to collect all data. It was divided into 10 parts. 


\section{Personal and sociodemographic characteristics}

The following data were collected: i) personal data, including the student's name, sex, adolescence stage, and age (early adolescent: $<14$ years, mid-adolescent: $14-16$ years, and late adolescent: $>16$ years) and ii) sociodemographic data, including the number of family members, crowding index, father's education, father's employment, mother's education, mother's employment, and family income. These data were summed in a total socioeconomic score following the methods used by Fahmy and El Sherbini ${ }^{13}$ with some modifications. The socioeconomic class was classified as "high", "middle", or "low".

\section{Social family environment}

The following data were collected: the people the adolescent was living with, the social status of the parents, the relationship between the parents, and the relationship between the patient and his or her parents and siblings. This was divided into three categories: "poor", "moderate", and "good" social family environment. ${ }^{4}$

\section{Medical history of diabetes}

The following data were collected: age of onset of diabetes, duration of disease, place of diagnosis, number of insulin injections/day, number of glucose monitorings/month, number of appointments/month, type of medication, number of hypoglycemic attacks within the last 3 months, number of hospital admissions in the last 6 months, and causes of dissatisfaction in diabetics care (eg, waiting time, shortage of medications).

\section{The DQoL measure for youth}

The DQoL Measure for Youth is a modification of the DQoL Instrument developed for the Diabetes Control and Complications Trial. ${ }^{14}$ The questionnaire consists of three parts: impact of diabetes, worry about diabetes, and satisfaction with life.

The worry about diabetes part consists of 11 items assessing worry about marriage, having children, death, job, education, body shape, complications of diabetes, and social relations. The adolescent was asked to answer each item on a 5-point scale ranging from 1 to 5 . A higher score reflects lower worry (better QoL). Total score was obtained by summing the scores for the 11 items and then a percentage total score was calculated.

The impact of diabetes part consists of 23 items assessing the impact of diabetes on physical (4 items), social (13 items), family (4 items), and school (2 items) aspects of the life of diabetics. The adolescent was asked to answer each item on a 5-point scale from 1 to 5 . A higher score reflects a lower impact of diabetes on the adolescent's life (better QoL). A total score was obtained by summing the scores for the 23 items and then a percentage total score was calculated.

The satisfaction with life part consists of 17 items assessing satisfaction with management ( 8 items), social life (6 items), and school life ( 3 items). The adolescent was asked to answer each item on a 5-point scale from 1 to 5 . The higher score reflects higher satisfaction with life (better QoL). Total score was obtained by summing the scores for the 17 items and then a percentage total score was calculated.

The total QoL was obtained by summing i) the total impact of diabetes, ii) worry about diabetes, and iii) satisfaction with life. The total sum of QoL range was divided into poor QoL $(<60 \%)$, moderate QoL $(60 \%-80 \%)$, and good QoL $(>80 \%)$.

The instrument was translated into the Arabic language by the researcher. Then, the preliminary translation was reviewed by the researchers and back-translated into English by other professionals in order to avoid bias and ensure accuracy. The Arabic version of the questionnaire was subjected to a pilot study among 48 adolescents. Test-retest reliability over a 2-week period was estimated $(r=0.85$, $P<0.001)$. The scale demonstrated an adequate Cronbach's internal consistency of 0.83 . The total QoL was obtained by summing the following variables: i) total impact of diabetes, ii) worry about diabetes, and iii) satisfaction with life. The total and percentage scores were calculated. The total sum of QoL was divided into poor QoL $(<60 \%)$, moderate QoL $(60 \%-80 \%)$, and good QoL $(>80 \%)$.

\section{Knowledge about diabetes}

The data collected included 16 items assessing the knowledge of diabetics about the appropriate glucose level for diabetics; symptoms of hyper- and hypoglycemia; complications; the effect of exercise, infections, and food on glucose level; sites of insulin injection; and glucose analysis in blood and urine. The answers were summed and then a percentage total score was calculated. The total sum of the knowledge score was graded as "poor knowledge" ( $\leq 60 \%)$, "fair knowledge" $(60 \%-80 \%)$, and "good knowledge" ( $\geq 80 \%) .{ }^{9}$

\section{Self-efficacy}

This questionnaire was designed to be similar to that developed by McCaul et a ${ }^{15}$ with some modifications. It consisted of 11 items to assess the adolescents' self-efficacy to medication (insulin intake), diet, and exercise. A percentage 
total score for self-efficacy was calculated. The total sum of self-efficacy was graded as "low" ( $\leq 60 \%)$, "moderate" $(60 \%-80 \%)$, and "high" ( $\geq 80 \%)$.

\section{Adherence to self-management}

A questionnaire composed of 10 items that covered adherence to different domains of self-management during the previous month was used. These domains were adherence to medication, adherence to a diabetic diet, adherence to glucose monitoring, adherence to medical appointments, and adherence to exercise. Each item was scored on a 3-point scale (never, sometimes, and always) with 1, 2, and 3 points assigned, respectively. A total score for adherence was obtained by summing the scores of these 10 items. The maximum total sum was 30 points and then the percentage total score was calculated and categorized as follows: "poor" ( $\leq 50 \%)$, "moderate" (>50\%-75\%), and "good" (>75\%) adherence to self-management.., 15

\section{Family contribution to diabetes self-care ${ }^{4}$}

A questionnaire composed of 11 items was used to assess the family's contribution to diabetes self-care. The answers were scored on a 3 -point scale (never $=1$, sometimes $=2$, and always $=3$ ) and then a percentage total score for family contribution was calculated. The total sum of family contribution was categorized as follows: "poor" $(\leq 60 \%)$, "moderate" (60\%-80\%), and "good" $(>80 \%)$ family contribution.

\section{Self-esteem of diabetics}

An Arabic version of the 25-item Coppersmith's Self-esteem Inventory ${ }^{21}$ adopted by Mossa and Al-Dosokki ${ }^{16}$ was administered to the adolescents to measure their self-esteem. The responses of the items were scored as 0 (for unfavorable response) or 1 (for favorable response). The range of total scores was from 0 to 25 and was divided into "high selfesteem" (more than $X+$ standard deviation [SD] or $>19.62$ ), "moderate self-esteem" (between $X \pm \mathrm{SD}$ or 12.12-19.62), and "low self-esteem" (less than $X-\mathrm{SD}$ or $<12.12$ ) and then the percentage score for total self-esteem was calculated for each patient.

\section{Depression}

The Arabic version of the Children's Depression Inventory $(\mathrm{CDI})^{17}$ was used, which included 27 multiple-choice items that covered an array of overt symptoms of depression, such as sadness, suicidal ideation, and sleep and appetite disturbances. Each CDI item assessed one symptom by presenting three choices that were graded from 0 to 2 in the direction of increasing psychopathology. Thus, the highest CDI total score was 54. The calculated cut-off score was 25 , and the categories were "not depressed" ( $<25$ points) and "depressed" ( $\geq 25$ points). The percentage score of total depression was then calculated for each patient.

\section{Record review}

Data were collected on the age, type of medication, glycemic control as measured by HbA1c (controlled diabetes $\leq 7.5$ and uncontrolled diabetes $>7.5$ ) based on International Society for Pediatric and Adolescent Diabetes Guidelines, ${ }^{18}$ and complications.

\section{Intervention phase}

\section{General objective and contents of the program}

The main goal of the education program was to fill the gap between adolescents' knowledge about diabetes and their adherence to diabetes management through a behavioral education program. The cognitive objective of the intervention was to describe the details of self-management while stressing the drawbacks of poor adherence. The affective objective was to help adolescents accept living with diabetes, increase their confidence in managing it, and improve their QoL. The behavioral objective of the program was to improve the self-management of patients.

\section{Selection of participants}

All targeted adolescents for intervention who agreed to participate were identified $(n=243)$. For logistic reasons, to complete the intervention before the end of the academic year (when the students are busy with their final examinations), and to avoid dropout of adolescents, the researchers implemented the program first for the 121 patients who attended the clinics for follow-up within a period of 4 months. The other 122 adolescents who did not receive the intervention were considered to be the control group. Both groups were tested 6 months after completion of the program.

\section{Selection of methods}

The intervention group $(\mathrm{n}=121)$ was divided into smaller groups containing about 15 adolescents each. Every group attended four 120-minute sessions over a period of 4 months, with one session every month (at their normal appointment at the clinic to get their medication). The program covered the following components: i) short- and long-term complications of diabetes, ii) medication and glucose monitoring, iii) nutrition and diabetes, and iv) exercise and foot care. 
The framework for the sessions was based on a multicomponent framework, including education and mutual support. Several teaching methods were used in the teaching settings, including group discussion, to allow the researcher to explore the main ideas that needed to be discussed. Group discussions also helped adolescents share information, gave them confidence, and motivated them to comply with the contents of the intervention. Counseling was used to individualize the behavioral objectives when needed. In addition, certain demonstrations helped the participants to understand some aspects of self-management such as insulin injection. Visual aids in the form of a white board and colored posters were used. The posters provided information about insulin injection sites, signs of hypoglycemia, signs of hyperglycemia, the diabetes food pyramid, and foot care. Demonstrations were used to explain insulin injection techniques and sites. The program was run by the investigators to ensure consistency, with the help of the health providers in the clinics to minimize logistic problems.

\section{Statistical analysis}

Data were collected, coded, analyzed, and tabulated using the Statistical Package for Social Sciences (SPSS Inc., Chicago, IL, USA) Version 17.1. The Pearson Chi-square test, Chi-square test for linear trends, and Fisher's exact test were used to compare the categorical data. The MannWhitney $U$ test, Kruskal-Wallis test, and Wilcoxon test were used to compare the quantitative data. Multiple linear regression was used to find the predictors of QoL score. Analysis of covariance was used to evaluate the impact of the program after adjusting for the results of the experimental and control groups before the intervention as covariates. Between-group effects (the intervention group minus the control group) were corrected for the baseline scores. A desirable effect of the intervention was determined by the positive difference between the experimental and the control groups.

\section{Ethical considerations}

A letter was sent by the school to the parents of each diabetic adolescent, describing the aim of the study. It asked for their agreement for their children to participate in an interview at the time the children attended the diabetes clinics. The parents who received information about the questionnaire could interact with the research team and learn about the study, its objectives, the possible benefits and risks of participating, and the child's rights and responsibilities. In this way, they could make a fully informed decision about whether or not to give permission for their child's participation in the intervention. The Research Committee of the High Institute of Public Health of Alexandria University approved the research after ensuring that it was in the minimal-risk category.

\section{Results}

The sample included 503 adolescents, of whom 218 (43.3\%) were males and $285(56.6 \%)$ were females. About half of the adolescents (49.5\%) were early adolescents (ages 12 to less than 14 years old), 39.6\% mid-adolescents (ages 14-16 years old), and 10.9\% late adolescents (ages 17 years or more). Overall, the mean age of the patients was $14.63 \pm 2.23$ years. There was no statistically significant difference between the sexes regarding age $\left(\chi^{2}=0.49\right.$, $P=0.91)$.

\section{QoL of adolescents with diabetes and glycemic control}

Table 1 shows the QoL of adolescents with diabetes by sex and QoL domain. The percentage mean score of total QoL for all adolescents was $76.51 \pm 9.79$. This percentage mean score was the lowest in the impact domain $(75.25 \pm 10.23)$ and the highest in the worry domain $(77.92 \pm 13.26)$. Patients with a good total QoL constituted $38 \%$ of all children. This percentage was higher for the satisfaction and worry domains (46.7\% and $49.1 \%$, respectively), whereas the percentage dropped to $33.2 \%$ in the impact domain. Male diabetic adolescents showed significantly better QoL in all domains $(P<0.001)$.

Table 2 shows the glycemic control of adolescents with diabetes by sex. About three-quarters (74.8\%) of adolescents had uncontrolled glucose levels according to the HbA1c level, and only $25.2 \%$ were controlled, with no statistically significant sex difference $\left(\chi^{2}=0.046\right.$, $P=0.64)$. The mean score of HbA1c for all adolescents was $10.53 \pm 1.90$.

\section{Predictors of QoL (Table 3)}

In the bivariate analysis, QoL was significantly associated with age $(P<0.001)$, levels of depression $(P<0.001)$, self-esteem $(P<0.001)$, the number of insulin injections/ day $\left(\chi^{2}=6.73, P<0.001\right)$, the number of hospital admissions per 6 months $\left(\chi^{2}=19.07, P<0.001\right)$, glycemic control $\left(\chi^{2}=47.72, P<0.001\right)$, satisfaction with health care services $\left(\chi^{2}=12.92, P<0.001\right)$, adherence $\left(\chi^{2}=33.19, P<0.001\right)$, self-efficacy $\left(\chi^{2}=38.34, P<0.001\right)$, and family contribution $\left(\chi^{2}=14.77, P<0.001\right)$. However, after adjustment for all 
Table I Distribution of adolescents with type I diabetes according to the level of quality of life (QoL) in different domains by sex. Higher scores denote lower worry, lower impact, higher satisfaction, and better total QoL

\begin{tabular}{|c|c|c|c|c|c|c|c|}
\hline \multirow{2}{*}{$\frac{\text { QoL }}{\text { Domains }}$} & \multicolumn{2}{|c|}{ Poor } & \multicolumn{2}{|c|}{ Moderate } & \multicolumn{2}{|c|}{ Good } & \multirow[t]{2}{*}{$\%$ mean score } \\
\hline & No. & $\%$ & No. & $\%$ & No. & $\%$ & \\
\hline \multicolumn{8}{|c|}{ Total worry } \\
\hline Male & 17 & 7.8 & 76 & 34.9 & 125 & 57.3 & $79.87 \pm 13.22$ \\
\hline Female & 34 & 11.9 & 129 & 45.3 & 122 & 42.8 & $76.42 \pm \mid 3.11$ \\
\hline \multirow[t]{2}{*}{ Total } & 51 & 10.1 & 205 & 40.8 & 247 & 49.1 & $77.92 \pm 13.26$ \\
\hline & $\chi^{2 \mathrm{a}}=$ & & & & & & $Z^{b}=3.37^{* *}$ \\
\hline \multicolumn{8}{|c|}{ Total impact } \\
\hline Male & 11 & 5.0 & 123 & 56.5 & 84 & 38.5 & $76.75 \pm 9.83$ \\
\hline Female & 25 & 8.8 & 177 & 62.1 & 83 & 29.1 & $74.11 \pm 10.40$ \\
\hline \multirow[t]{2}{*}{ Total } & 36 & 7.2 & 300 & 59.6 & 167 & 33.2 & $75.25 \pm 10.23$ \\
\hline & $\chi^{2 a}=$ & & & & & & $Z^{b}=2.72^{* *}$ \\
\hline \multicolumn{8}{|c|}{ Total satisfaction with life } \\
\hline Male & 10 & 4.6 & 77 & 35.3 & $|3|$ & 60.1 & $80.89 \pm 10.53$ \\
\hline Female & 41 & 14.4 & 140 & 49.1 & 104 & 36.5 & $74.02 \pm 13.03$ \\
\hline \multirow[t]{2}{*}{ Total } & 51 & 10.2 & 217 & 43.1 & 235 & 46.7 & $77.00 \pm 12.47$ \\
\hline & $\chi^{2 \mathrm{a}}=$ & & & & & & $Z^{b}=6.00 * *$ \\
\hline \multicolumn{8}{|l|}{ Total QoL } \\
\hline Male & 6 & 2.8 & 115 & 52.7 & 97 & 44.5 & $78.77 \pm 8.92$ \\
\hline Female & 20 & 7.0 & $|7|$ & 60.0 & 94 & 33.0 & $74.51 \pm 10.03$ \\
\hline \multirow[t]{2}{*}{ Total } & 26 & 5.2 & 286 & 56.8 & 191 & 38.0 & $76.36 \pm 9.79$ \\
\hline & $\chi^{2 a}=$ & & & & & & $Z^{b}=4.716^{* *}$ \\
\hline
\end{tabular}

Notes: aChi-square test for linear trend was applied; bMann-Whitney $U$ test was applied; **significant at $P<0.0$ I.

these significant variables, poorer QoL was significantly associated with older age $(P<0.001)$, more hospital admissions in the last 6 months $(P=0.006)$, higher levels of depression $(P<0.001)$, poor self-esteem $(P<0.001)$, and poor self-efficacy $(P<0.001)$.

\section{Impact of the educational intervention program on diabetes QoL (Table 4)}

There was significant deterioration in all domains of QoL in the experimental group after intervention. However, this deterioration was significantly less so than in the control group. The between-group effects were in favor of the intervention group in the physical impact $(P=0.006)$, social impact $(P<0.001)$, school impact $(P=0.03)$, satisfaction with social life $(P<0.001)$, satisfaction with school life $(P<0.001)$, and total satisfaction $(P=0.002)$ domains.

\section{Impact of educational intervention program on possible determinants of diabetes QoL and glycemic control (Table 5)}

Table 4 shows the percentage mean difference of QoL determinants in the experimental and control groups before and after intervention. The positive effect of educational intervention was supported by the significance of the between-group effect on total knowledge $(P<0.001)$, total adherence $(P<0.001)$, self-efficacy $(P<0.001)$, family contribution $(P<0.001)$, and HbA1c $(P<0.001)$. The experimental group showed a significant increase in the mean score of adherence, whereas the control group showed a significant reduction. With regard to knowledge, although both groups showed a significant increase in the mean score, this increase was significantly higher among

Table 2 Distribution of adolescents with type I diabetes according to glycemic control by sex

\begin{tabular}{|c|c|c|c|c|c|c|c|}
\hline \multirow[t]{2}{*}{ Glycemic control } & \multicolumn{2}{|c|}{ Males } & \multicolumn{2}{|c|}{ Females } & \multicolumn{2}{|c|}{ Total } & \multirow[t]{2}{*}{ Sex difference } \\
\hline & No. & $\%$ & No. & $\%$ & No. & $\%$ & \\
\hline Controlled & 54 & 24.8 & 73 & 25.6 & 127 & 25.2 & $\chi^{2 a}=0.046, P=0.81$ \\
\hline Uncontrolled & 164 & 75.2 & 212 & 74.4 & 376 & 74.8 & \\
\hline Total & 218 & 100.0 & 285 & 100.0 & 503 & 100.0 & \\
\hline$X \pm$ standard deviation & \multicolumn{2}{|c|}{$10.38 \pm 1.7 \mid$} & \multicolumn{2}{|c|}{$10.65 \pm 2.02$} & \multicolumn{2}{|c|}{$10.53 \pm 1.90$} & $Z^{b}=1.60, P=0.12$ \\
\hline
\end{tabular}

Notes: ${ }^{a}$ Pearson Chi-squared test was applied; ' $M a n n-W h i t n e y ~ U$ test was applied. 
Table 3 Distribution of adolescents with type I diabetes according to personal, disease, and health care characteristics and the percentage mean quality of life score. $P$ values were adjusted only for significant variables in the univariate analyses. Higher scores denote lower worry, lower impact, higher satisfaction, and better total quality of life

\begin{tabular}{|c|c|c|c|c|}
\hline \multirow[t]{2}{*}{ Characteristics } & \multicolumn{2}{|c|}{ Total } & \multirow[t]{2}{*}{$\%$ mean score } & \multirow[t]{2}{*}{ Adjusted $P$ value } \\
\hline & No. & $\%$ & & \\
\hline \multicolumn{5}{|c|}{ A. Personal characteristics } \\
\hline \multicolumn{5}{|l|}{ Sex } \\
\hline Male & 218 & 43.3 & $78.77 \pm 8.92$ & \\
\hline \multirow[t]{2}{*}{ Female } & 285 & 56.7 & $74.51 \pm 10.03$ & \\
\hline & & & $Z^{\mathrm{a}}=4.716, P<0.00 I^{*}$ & 0.267 \\
\hline \multicolumn{5}{|l|}{ Stage of adolescence } \\
\hline Early ( 12 to $<14$ years) & 249 & 49.5 & $78.80 \pm 8.85$ & \\
\hline Mid (14-16 years) & 199 & 39.6 & $74.09 \pm 10.22$ & \\
\hline \multirow[t]{2}{*}{ Late ( $>16$ years) } & 55 & 10.9 & $73.49 \pm 9.68$ & \\
\hline & & & $\chi^{2 b}=29.709, P<0.00 I^{*}$ & $<0.001$ \\
\hline \multicolumn{5}{|l|}{ Socioeconomic level } \\
\hline Low & 191 & 38.0 & $74.01 \pm 9.70$ & \\
\hline Moderate & 197 & 39.1 & $76.02 \pm 9.41$ & \\
\hline \multirow[t]{2}{*}{ High } & 115 & 22.9 & $80.84 \pm 9.12$ & \\
\hline & & & $\chi^{2 b}=36.414, P<0.001 *$ & 0.075 \\
\hline \multicolumn{5}{|c|}{ Social family environment } \\
\hline Poor & 92 & 18.3 & $71.67 \pm 8.61$ & \\
\hline Moderate & 221 & 43.9 & $75.74 \pm 9.74$ & \\
\hline \multirow[t]{2}{*}{ Good } & 190 & 37.8 & $79.34 \pm 9.40$ & \\
\hline & & & $\chi^{2 b}=42.517^{*}, P<0.00 I^{*}$ & 0.861 \\
\hline \multicolumn{5}{|l|}{ Self-esteem } \\
\hline Low & 90 & 17.9 & $66.94 \pm 8.74$ & \\
\hline Moderate & 328 & 65.2 & $77.03 \pm 8.51$ & \\
\hline \multirow[t]{2}{*}{ High } & 85 & 19.9 & $83.74 \pm 7.60$ & \\
\hline & & & $\chi^{2 b}=\mid 32.77, P<0.00 I^{*}$ & $<0.001$ \\
\hline \multicolumn{5}{|l|}{ Depression } \\
\hline Depressed & 67 & 13.3 & $65.41 \pm 7.04$ & \\
\hline \multirow[t]{2}{*}{ Not depressed } & 436 & 86.7 & $78.04 \pm 9.04$ & \\
\hline & & & $Z=9.54, P<0.00 I^{*}$ & $<0.001$ \\
\hline \multicolumn{5}{|c|}{ B. Disease characteristics } \\
\hline \multicolumn{5}{|l|}{ Age of onset } \\
\hline$<6$ years & 79 & 15.7 & $77.34 \pm 9.73$ & \\
\hline $6-10$ years & 158 & 31.4 & $78.15 \pm 9.83$ & \\
\hline \multirow[t]{2}{*}{$>10$ years } & 266 & 52.9 & $75.00 \pm 9.61$ & \\
\hline & & & $\chi^{2 b}=0.921, P=0.631$ & \\
\hline \multicolumn{5}{|l|}{ Duration of disease } \\
\hline$<$ I year & 105 & 20.9 & $76.10 \pm 11.21$ & \\
\hline $\mathrm{I}-5$ years & 233 & 46.3 & $77.23 \pm 8.87$ & \\
\hline$>5$ years & 165 & 32.8 & $75.29 \pm 10.00$ & \\
\hline & & & $\chi^{2 b}=3.49, P=0.174$ & \\
\hline Number of insulin inj & & & & \\
\hline Once or twice/day & 322 & 64.5 & $75.67 \pm 9.63$ & \\
\hline Three + /day & 177 & 35.5 & $77.67 \pm 10.01$ & \\
\hline & & & $\chi^{2 b}=5.928, P=0.04^{*}$ & 0.325 \\
\hline Number of hypoglyce & $\mathrm{s} / 3 \mathrm{mc}$ & & & \\
\hline Never & 168 & 33.4 & $77.67 \pm 9.38$ & \\
\hline Once & 68 & 13.5 & $77.28 \pm 9.91$ & \\
\hline Twice & 84 & 16.7 & $75.01 \pm 9.78$ & \\
\hline Three or more & 183 & 36.4 & $75.42 \pm 10.01$ & \\
\hline & & & $\chi^{2 b}=3.298, P=0.098$ & \\
\hline
\end{tabular}

(Continued) 
Table 3 (Continued)

\begin{tabular}{|c|c|c|c|c|}
\hline \multirow[t]{2}{*}{ Characteristics } & \multicolumn{2}{|c|}{ Total } & \multirow[t]{2}{*}{$\%$ mean score } & \multirow[t]{2}{*}{ Adjusted $P$ value } \\
\hline & No. & $\%$ & & \\
\hline \multicolumn{5}{|c|}{ Number of hospital admissions/6 months } \\
\hline Never & 282 & 56.1 & $77.95 \pm 9.11$ & \\
\hline Once & 125 & 24.9 & $76.12 \pm 9.90$ & \\
\hline Twice & 48 & 9.5 & $71.37 \pm 10.05$ & \\
\hline \multirow[t]{2}{*}{ Three or more } & 48 & 9.5 & $72.58 \pm 10.59$ & \\
\hline & & & $\chi^{2 \mathrm{~b}}=21.43, P<0.00 I^{*}$ & 0.006 \\
\hline \multicolumn{5}{|l|}{ Glycemic control } \\
\hline Controlled & 127 & 25.2 & $81.78 \pm 8.12$ & \\
\hline \multirow[t]{2}{*}{ Uncontrolled } & 376 & 74.8 & $74.53 \pm 9.64$ & \\
\hline & & & $Z^{\mathrm{a}}=7.203, P<0.00 I^{*}$ & 0.085 \\
\hline \multicolumn{5}{|l|}{ Complications } \\
\hline No complications & 466 & 92.6 & $76.86 \pm 9.86$ & \\
\hline \multirow[t]{2}{*}{ Complications } & 37 & 7.4 & $69.98 \pm 8.95$ & \\
\hline & & & $Z^{\mathrm{a}}=3.892, P<0.00 I^{*}$ & 0.053 \\
\hline \multicolumn{5}{|c|}{ C. Health care characteristics } \\
\hline \multicolumn{5}{|l|}{ Type of care } \\
\hline Insured & 439 & 87.3 & $76.33 \pm 9.86$ & \\
\hline \multirow[t]{2}{*}{ Noninsured } & 64 & 12.7 & $76.54 \pm 9.36$ & \\
\hline & & & $Z^{\mathrm{a}}=0.157, P=14.6$ & \\
\hline \multicolumn{5}{|c|}{ Satisfaction with health care service } \\
\hline Satisfied & $24 I$ & 47.9 & $77.87 \pm 9.44$ & \\
\hline \multirow[t]{2}{*}{ Unsatisfied } & 262 & 52.1 & $74.97 \pm 9.91$ & \\
\hline & & & $Z^{\mathrm{a}}=3.169, P=0.002^{*}$ & 0.670 \\
\hline \multicolumn{5}{|l|}{ Adherence } \\
\hline Poor & 39 & 7.8 & $68.04 \pm 8.97$ & \\
\hline Moderate & 266 & 52.9 & $75.30 \pm 8.48$ & \\
\hline \multirow[t]{2}{*}{ Good } & 198 & 39.3 & $79.42 \pm 10.35$ & \\
\hline & & & $\chi^{2 b}=51.9, P<0.001 *$ & 0.369 \\
\hline \multicolumn{5}{|l|}{ Knowledge } \\
\hline Fair & 55 & 10.9 & $76.42 \pm 8.29$ & \\
\hline \multirow[t]{2}{*}{ Good } & 448 & 89.1 & $76.35 \pm 9.96$ & \\
\hline & & & $Z^{a}=0.37, P=57.3$ & \\
\hline \multicolumn{5}{|l|}{ Self-efficacy } \\
\hline Low & 77 & 15.3 & $70.86 \pm 10.09$ & \\
\hline Moderate & 199 & 39.6 & $74.26 \pm 9.32$ & \\
\hline \multirow[t]{2}{*}{ High } & 227 & 45.1 & $80.06 \pm 8.63$ & \\
\hline & & & $\chi^{2 \mathrm{~b}}=64.682, P<0.00 I^{*}$ & $<0.001$ \\
\hline \multicolumn{5}{|c|}{ Family contribution } \\
\hline Poor & $26 I$ & 51.9 & $74.49 \pm 9.46$ & \\
\hline Moderate & 212 & 42.1 & $77.68 \pm 9.87$ & \\
\hline \multirow[t]{2}{*}{ Good } & 30 & 6.0 & $83.24 \pm 7.46$ & \\
\hline & & & $\chi^{2 \mathrm{~b}}=30.192, P<0.00 I^{*}$ & 0.541 \\
\hline
\end{tabular}

Notes: ${ }^{a}$ Mann-Whitney $U$ test was applied; ' Kruskal-Wallis test was applied; *significant at $P<0.0$ I.

the experimental group. Mean scores of both self-efficacy and family contribution showed no significant change in the experimental group, whereas significant reductions were detected in the control group. Although HbAlc showed no significant improvement from the baseline by the experimental group $(0.18 \%$ reduction), a significant adverse increase in the mean figure was detected in the control group $(0.25 \%$ increase $)$.

\section{Discussion}

In this study of the QoL and its determinants in diabetic adolescents in Alexandria, we found that the mean total QoL score was $76.36 \% \pm 9.79 \%$. This figure is similar to that from a study conducted by $\mathrm{Cara}^{11}(73 \%)$ in Europe, less than that from a study by Lafel et al ${ }^{19}(81.3 \% \pm 4.57 \%)$ in the US, and higher than that reported by Sawyer et $\mathrm{al}^{20}(61.4 \% \pm 15.4 \%)$ in the US. Generally, lower QoL scores were associated with 

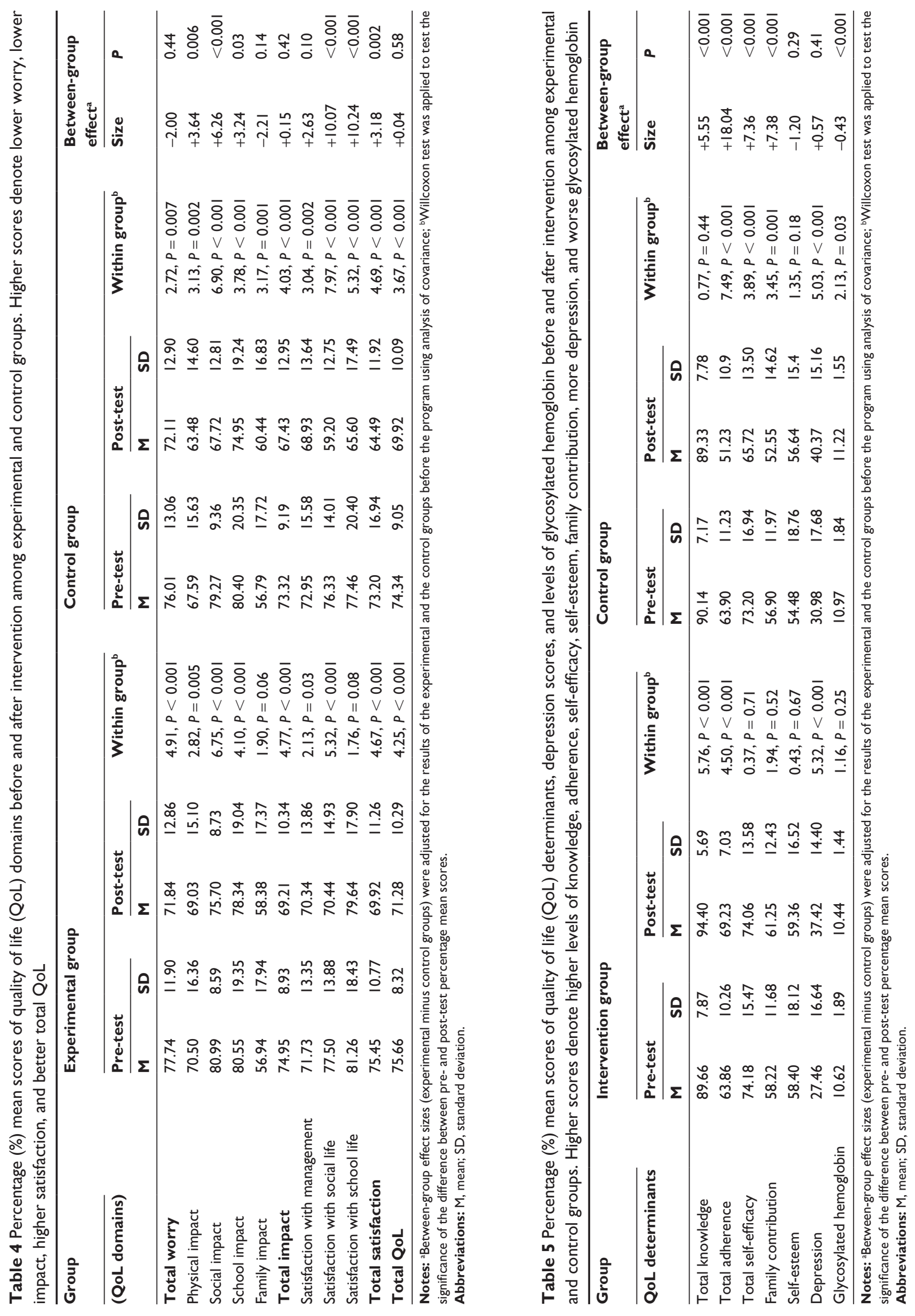
old age, poor glycemic control, an increasing number of hypoglycemic episodes, complications, low levels of education and outcome, self-reported depression, and female gender. ${ }^{5}$ The present study showed that significant predictors of poor QoL were older age, more hospital admissions in the last 6 months, higher levels of depression, poor self-esteem, and poor self-efficacy.

The results of the current work demonstrate that there was a significant reduction in the total QoL and its four domains following the intervention in the experimental group as well as in the control group. These findings contradicted those of other studies. ${ }^{21,22}$ The inability to detect improvements in adolescent QoL in the experimental group might have resulted from an insufficient number of participants or inadequate time to observe such changes. However, the between-group differences were in favor of the experimental group in the impact and satisfaction QoL domains. The promise of a short intervention of minimal cost providing immediate health benefits by preventing deterioration of QoL and possibly preventing long-term diabetes complications is worthy of longer-term investigation. ${ }^{23}$

The program in the present study had a nonsignificant effect on self-esteem. This was also true for depression. These results may reflect the need to combine psychoeducational techniques (eg, coping skills or adjustment techniques) with behavioral education to improve psychological aspects in adolescents. ${ }^{24}$ Moreover, decreased self-esteem and an increased rate of depression in adolescents may pose a question about using the fear-appeal technique with adolescents.

The importance of knowledge in health education must not be ignored, because increased knowledge is the first step toward health behavior modification; thus, many studies have incorporated knowledge building into their intervention programs. ${ }^{9,22,25,26}$ However, a systematic review reported that the effect of educational intervention on diabetes knowledge was unclear, with 12 of 30 studies reporting a significant impact. ${ }^{27}$ The present study had a positive effect on knowledge.

According to the previously mentioned systemic review, ${ }^{27} 10$ of 21 studies reported improvement in the area of management/regimen adherence. The current findings demonstrated a significant impact of the program on adherence. There was improvement in adherence in both groups, with significantly more improvement in the experimental group than in the control group. The program helped to maintain optimal self-efficacy in the experimental group, whereas self-efficacy in the control group exhibited significant deterioration. From the previous results, it can be deduced that self-efficacy of adolescents can be enhanced by using the parameters of social learning theory such as specific techniques of direct self-reinforcement. ${ }^{28}$

Research had found that family contribution decreased with increased duration of diabetes ${ }^{4}$ as parents started to transfer responsibility of disease management to their children. This was evidenced in the present study where a significant reduction in family contribution mean score was detected among the control group, although this score was preserved in the experimental group, resulting in a significant between-group effect. This finding was in agreement with the finding of a family-focused teamwork intervention where more families in the teamwork group increased or maintained family involvement than in the standard care group. ${ }^{23}$

Deterioration of glycemic control is a common problem in adolescents with diabetes. ${ }^{29}$ The effect of educational programs on glycemic control differs among studies. ${ }^{8-10}$ In the present study, there was a nonsignificant improvement in the level of $\mathrm{HbA} 1 \mathrm{c}$ from the baseline in the experimental group compared with a significant adverse increase in the control group. Although HbA1c showed no significant improvement from the baseline by the experimental group $(0.18 \%$ reduction), a significant adverse increase in the mean figure was detected in the control group $(0.25 \%$ increase), leading to a significant desirable between-effect size $(-0.43 \%)$.

Although a positive relation between adherence and glycemic control has long been assumed, there is some evidence to the contrary. ${ }^{30}$ In the present study, there was no improvement in $\mathrm{HbA} 1 \mathrm{c}$ in the experimental group, yet there was an improvement in total adherence. This may be explained by the fact that some aspects of adherence (such as diet) may have deteriorated, whereas other aspects (such as exercise and glucose monitoring) may have improved. In addition, hormonal effects in adolescence may play a role in this lack of improvement. However, further investigation of the adherence-glycemia relationship is warranted.

This study has some limitations. First, there was a lack of a true control group. This may lessen the validity of the conclusions as to the intervention actually being beneficial. Second, an inability to detect within- or between-group differences in adolescent QoL and/or glycemic control might have resulted from an insufficient number of participants or inadequate time to observe such changes. Third, process evaluation was not conducted. Fourth, the missing data in 
the survey and the intervention phases may affect the validity of the conclusion.

\section{Conclusion}

Aside from these limitations, the present study showed that the level of QoL among Egyptian adolescents with type 1 diabetes is comparable with figures from many Western countries. Significant predictors of poor QoL were older age, more hospital admissions in the last 6 months, higher levels of depression, poor self-esteem, and poor self-efficacy.

The program was found to have a positive effect on total knowledge, total adherence, self-efficacy, and family contribution. Although significant deteriorations were detected in all domains of QoL after intervention, the intervention could be considered a safeguard against the increased deterioration that could have occurred with no intervention. This was also the case for glycemic control. This study is particularly relevant to health professionals who work with adolescents and their families. The finding that deterioration of QoL and/or glycemic control can be prevented by using a short intervention at a minimal cost is encouraging.

The following approaches are recommended. First, health education must be an integral part of diabetes management in all diabetic clinics and hospitals rather than a set of instructions given once at the beginning of the follow-up. Education of children and adolescents with type 1 diabetes and their families needs to be supported by psychosocial and possibly family therapy interventions. Second, continuous training of health staff (doctors, nurses, and lab workers) is needed for the implementation of educational interventions to raise awareness about the importance of health education among adolescents and to train them in how to communicate with patients so they can keep adolescents motivated for selfmanagement and detect early psychological stresses. Third, further research is needed to test efficacious interventions in terms of their effectiveness in clinical practice, prior to widespread implementation in practice settings.

\section{Acknowledgements}

This study was approved by the Research Committee of the High Institute of Public Health, Alexandria University, Alexandria, Egypt. We thank the editing service office at King Abdullah International Medical Research Center (KAIMRC), King Saud Bin-Abdulaziz University for Health Sciences, Riyadh, Saudi Arabia, for the English language editing of the manuscript via a specialist English language copy editor (American Journal Experts).

\section{Disclosure}

The authors declare that they have no competing interests.

\section{References}

1. Faulkner MS. Quality of life for adolescents with type I diabetes: parental and youth perspectives. Paediatr Nurs. 2003;29(5):362-368.

2. Delamater AM. Quality of life in youths with diabetes. Diabetes Spectr. 2000;13:42.

3. Burroughs TE, Desikan R, Waterman BM, et al. Development and validation of the diabetes quality of life brief clinical inventory. Diabetes Spectr. 2004;17:41-49.

4. Faulkner MS, Chang LI. Family influence on self-care, quality of life, and metabolic control in school-age children and adolescents with type 1 diabetes. Paediatr Nurs. 2007;22(1):59-68.

5. Levine BS, Anderson BJ, Butler DA, et al. Predictors of glycemic control and short-term adverse outcomes in youth with type 1 diabetes. J Pediatr. 2001;139:197-203.

6. Tang TS, Funnell MM, Robert M, Anderson RM. Group education strategies for diabetes self-management. Diabetes Spectr. 2006;19: 99-105.

7. Funnell MM, Anderson RM. Empowerment and self-management of diabetes. Clin Diabetes. 2004;22:123-127.

8. Ellis DA, Frey MA, Naar-King S, et al. Use of multi-systemic therapy to improve regimen adherence among adolescents with type 1 diabetes in chronic poor metabolic control: a randomized controlled trial. Diabetes Care. 2005;28:1604-1610.

9. Matam P, Kumaraiah V, Munichoodappa C, et al. Behavioural intervention in the management of compliance in young type I diabetics. J Assoc Physicians. 2000;48(10):967-971.

10. Tang S, Gillard M, Funnell M, et al. Developing a new generation of ongoing diabetes self-management support interventions. Diabetes Educ. 2005;31(1):91-97.

11. Cara JF. Psychosocial Aspects of Type I Diabetes Mellitus. European Association for the Study of Diabetes, ed; 2003.

12. Murphy H, Rayman G, Skinner T. Psycho-educational interventions for children and young people with type 1 diabetes. Diabet Med. 2006;23(9):935-943.

13. Fahmy SI, El Sherbinie AF. Determining simple parameters for social classifications for health research. Bulletin of HIPH. 1983;13: 95-107.

14. Ingersol GM, Marrero DG. A modified quality of life measure for youth: psychometric properties. Diabetes Educ. 1991;17:114-118.

15. McCaul KD, Glasgow RE, Schafer LC. Diabetes regimen behavior predicting adherence. Med Care. 1987;25(9):868-881.

16. Mossa FA, Al-Dosokki MA. Assessment of Childhood Self-esteem. Cairo: AL-Nahdah Al-Mesreyya Press; 1981.

17. Kovacs M. Rating scales to assess depression in school aged children Acta Pedopsychiat. 1981;46:305-315.

18. ISPAD. ISPAD clinical practice consensus guidelines 2009. http://www. ispad.org/FileCenter.html?CategoryID=5. Accessed June 16, 2010.

19. Laffel LM, Connell A, Vangsness L, et al. General quality of life in youth with type 1 diabetes: relationship to patient management and diabetes-specific family conflict. Diabetes Care. 2003;26:3067-3073.

20. Sawyer M, Reynolds K, Couper J, et al. Health related quality of life of children and adolescents with chronic illness: a two year prospective study. Qua Life Research. 2003;1:11-23.

21. Kaplan RM, Hartwell SL, Wilson DK, Wallace JP. Effects of diet and exercise interventions on control and quality of life in non-insulin-dependent diabetes mellitus. J Gen Intern Med. 1987;2(4): $220-228$.

22. Von Sengbusch S, Muller-Godeffroy E, Hager S, et al. Mobile diabetes education and care: intervention for children and young people with type 1 diabetes in rural areas of northern Germany. Diabet Med. 2006; 23(2):122-127. 
23. Laffel LMB, Vangsness L, Connell A, et al. Impact of ambulatory, family-focused teamwork intervention on glycemic control in youth with type 1 diabetes. J Pediatr. 2003;142:409-416.

24. Mendez FJ, Belendez M. Effects of a behavioral intervention on treatment adherence and stress management in adolescents with IDDM. Diabetes. 1997;20:1370-1375.

25. Rey JM, Anderson J. Assessing regimen adherence of adolescents with type 1 diabetes. Diabetes Care. 2006;29:2263-2267.

26. Karaguzel G, Bircan I, Erisir S, Bundak R. Metabolic control and educational status in children with type 1 diabetes: effects of a summer camp and intensive insulin treatment. Acta Diabetol. 2005;42: 156-161.

27. Couch R, Jetha M, Dryden DM, et al. Diabetes education for children with type 1 diabetes mellitus and their families. Report prepared for the Agency for Healthcare Research and Quality, US Department of Health and Human Services, AHRQ Publication No. 08-E011, April 2008. Accessed January 31, 2011.
28. Glanz K, Lewis FM, Rimer BK, editors. Health Behavior and Health Education. San Francisco, Oxford: Jossey-Bass Publishers; 1990: $172-173$.

29. Daneman D, Wolfson DH, Becker DJ, et al. Factors affecting glycosylated hemoglobin values in children with insulin-dependent diabetes. J Pediatr. 1981;99:847-853.

30. Wysocki T, Greco P, Harris MA, et al. Behavior therapy for families of adolescents with diabetes: maintenance of treatment effects. Diabetes Care. 2001;24:441-446.

\section{Publish your work in this journal}

The International Journal of General Medicine is an international, peer-reviewed open-access journal that focuses on general and internal medicine, pathogenesis, epidemiology, diagnosis, monitoring and treatment protocols. The journal is characterized by the rapid reporting of reviews, original research and clinical studies across all disease areas.
A key focus is the elucidation of disease processes and management protocols resulting in improved outcomes for the patient. The manuscript management system is completely online and includes a very quick and fair peer-review system. Visit http://www.dovepress.com/ testimonials.php to read real quotes from published authors.

Submit your manuscript here: http://www.dovepress.com/international-journal-of-general-medicine-journal 